\title{
HIGH INCIDENCE AND CLINICAL SIGNIFICANCE OF MYC REARRANGEMENTS IN PRIMARY CUTANEOUS DIFFUSE LARGE B-CELL LYMPHOMA, LEG TYPE
}

Anne M.R. Schrader, $\mathrm{MD}^{1}$, Patty M. Jansen, $M D^{2} \mathrm{PhD}^{1}$, Maarten H. Vermeer, MD PhD ${ }^{2}$, J.K. (Karin) Kleiverda ${ }^{1}$, Joost S.P. Vermaat, $\mathrm{MD} \mathrm{PhD}^{3}$, and Rein Willemze, MD PhD ${ }^{2}$

${ }^{1}$ Department of Pathology, ${ }^{2}$ Department of Dermatology, and ${ }^{3}$ Department of Hematology, Leiden University Medical Center, Leiden, The Netherlands

\section{Corresponding author:}

Anne M. R. Schrader, MD

Leiden University Medical Center

Department of Pathology

P.O. box 9600

2300 RC Leiden

The Netherlands

Telephone: +31 71 - 5266503

Fax number: +31 71 - 5266952

E-mail address: a.m.r.schrader@lumc.nl

Conflicts of Interest and Source of Funding:

M.V. is a member of an entity's Board of Directors or advisory committees of the Innate Pharma safety board for IPH4102-101. For the remaining authors none were declared. 
ABSTRACT

Primary cutaneous diffuse large B-cell lymphoma, leg type (PCDLBCL-LT) and primary cutaneous follicle center lymphoma (PCFCL) are cutaneous B-cell lymphomas $(\mathrm{CBCL})$ with different clinical characteristics and behavior. PCDLBCL-LT is the most aggressive $C B C L$ with a relatively poor prognosis. In nodal diffuse large B-cell lymphoma (DLBCL), rearrangements of the MYC gene, especially in combination with a second hit in $B C L 2$ and/or BCL6, and double protein expression of MYC and BCL2 (DE) are adverse prognostic factors. As the clinical significance of these factors in $\mathrm{CBCL}$ is largely unknown, we studied the frequency and prognostic value of $M Y C$ rearrangements and DE in a cohort of 44 patients with PCDLBCL-LT and 17 patients with PCFCL. Compared with nodal DLBCL (9-14\%), the PCDLBCL-LT patients had a high incidence of MYC rearrangements (32\%), but only two patients (4\%) had a second hit, both with BCL6. PCDLBCL-LT patients with a MYC rearrangement showed an inferior disease-specific survival (Log-rank, $p=0.036$ ) and disease-free survival (Log-rank, $p=0.028$ ), but no significant adverse effect on overall survival (Log-rank, $p=0.157$ ) at 5 years compared with patients without a MYC rearrangement. DE, present in $65 \%$ of the PCDLBCL-LT patients, was not associated with reduced survival. In the PCFCL group, MYC rearrangements and DE were not detected. In conclusion, this study identifies a high incidence of MYC rearrangements in PCDLBCL-LT compared with nodal DLBCL and further shows that a MYC rearrangement is an inferior prognostic marker in these patients. Therefore, our data suggest that it is useful to perform MYC-FISH in all newly diagnosed PCDLBCL-LT patients. 


\section{INTRODUCTION}

Primary cutaneous diffuse large B-cell lymphoma, leg type (PCDLBCL-LT) and primary cutaneous follicle center lymphoma (PCFCL) are both cutaneous B-cell lymphomas (CBCL) with a large cell morphology. Whereas PCFCL patients have an excellent prognosis with a 5-year diseasespecific survival (DSS) of over 95\%, PCDLBCL-LT is a more aggressive type of CBCL with a 5-year DSS of $\sim 55 \%$.(1) So far, the only adverse prognostic factors that have been identified are presentation with multiple skin lesions, loss of 9p.21 (CDKN2A/B), and hotspot mutations in MYD88 L265P.(2-4)

In 9 to $14 \%$ of nodal diffuse large B-cell lymphomas (DLBCLs), rearrangements of the MYC gene are present, which is associated with a poor prognosis.(5-8) In over half of the cases, MYC rearrangements occur in combination with a second hit in the BCL2 and/or BCL6 genes and these patients demonstrate an even worse outcome with a median overall survival (OS) reported between 0.2 and 1.5 years. $(5,8-12)$ In the 2017 revision of the WHO classification, these so called "double hit lymphomas" (or "triple hit lymphomas") are classified as a separate disease entity with a very aggressive behavior.(13) In addition, 19 to $34 \%$ of the DLBCL patients have double protein expression of MYC and BCL2 (DE), but lack genetic rearrangements in these genes, demonstrating an intermediate survival between DLBCL with single or no expression of MYC and BCL2, and DLBCL with double or triple hits.(14-16) Regarding the cell-of-origin, single MYC rearrangements and double hits with BCL6 show a rather equal distribution between the germinal center B-cell (GCB) and the activated $B$-cell $(A B C)$ subtypes, whereas double hits with $B C L 2$ and triple hits are characteristic for GCB-DLBCL and do not seem to occur in ABC-DLBCL.(17) In addition, DE is more common in the $A B C$ subtype.(16)

Gene-expression profiling of CBCL showed that PCDLBCL-LT is similar to the ABC-subtype and PCFCL to the GCB-subtype of nodal DLBCL.(18) Correspondingly, the vast majority of PCDLBCL-LT patients expresses MUM1 and BCL2, approximately two-third is positive for BCL6, while CD10 expression is usually lacking. $(19,20)$ Molecular studies identified highly recurrent mutations in genes that are predominantly involved in the NFk $\beta$-signalling pathway, such as MYD88, PIM1, and CD79B.(21-23) The presence of MYC rearrangements and MYC protein expression has only been studied in a small number of patients with $\mathrm{CBCL}$ with very diverse results and the relation between MYC rearrangements and survival is unknown. $(22,24-26)$

Considering the small number of studied $\mathrm{CBCL}$ patients and the clinical relevance in nodal DLBCL, the purpose of this study was to evaluate the frequency and prognostic significance of MYC rearrangements, either alone or in combination with $B C L 2$ and/or BCL6 rearrangements, and of DE in a relatively large cohort of PCDLBCL-LT and PCFCL patients. 


\section{MATERIALS AND METHODS}

All patients with PCDLBCL-LT, consecutively diagnosed in the Leiden University Medical Center (LUMC), Leiden, The Netherlands between 2000 and 2017 were selected from the Cutaneous Lymphoma database $(n=47)$. In addition, a random selection of patients with PCFCL, diagnosed in the same period, were included $(n=20)$. In all cases, diagnoses was confirmed by a panel of dermatologists and pathologist during one of the regular meetings of the Dutch Cutaneous Lymphoma Group, according to the criteria of the WHO-EORTC classification.(1) In all patients, the presence of extracutaneous disease at time of diagnosis was excluded by standard staging procedures, consisting of a combination of physical examination, complete blood count and chemistry, chest radiography, computerized tomography of thorax and abdomen, and bone marrow cytology and/or histology. Clinical presentation and follow-up data were collected from the registry of the Dutch Cutaneous Lymphoma Group and/or from the medical records. Patients were excluded in case of insufficient tissue samples for molecular analysis ( $n=3$ for PCDLBCL-LT; $n=3$ for PCFCL). The study was performed in accordance with the Code Proper Secondary Use of Human Tissue established by the Dutch Federation of Medical Sciences, as approved by the medical ethics committee of the LUMC (B16.048).

\section{Immunohistochemistry}

The pretreatment formalin-fixed and paraffin-embedded skin biopsies from the included patients were collected from the archives of the Department of Pathology of the LUMC. Sections of $3 \mu \mathrm{m}$ were immunostained with antibodies against MYC (clone Y69, diluted 1:100; ABCAM), BCL2 (clone 124, diluted 1:80; Dako, Glostrup, Denmark), BCL6 (clone PG-B6p, diluted 1:100; Invitrogen), CD20 (clone L26, diluted 1:800; Dako) and/or CD79A (clone JCD117, diluted 1:100; Dako), CD10 (clone 56C6, diluted 1:20; Dako), MUM1 (clone MUM1p, diluted 1:100; Dako), and IgM (polyclonal, diluted 1:500; Dako) using the Dako Autostainer Link 48 (Dako) according to standard staining procedures. Immunohistochemical expression by the tumor cells was estimated by the authors A.M.R.S., P.M.J., and R.W., until consensus was reached. MYC expression was scored with the standard cutoff value of $40 \%$.(27) The other immunohistochemical markers were scored with a cutoff value of $30 \%$ for CD10, BCL6, and MUM1, and 50\% for BCL2 and IgM. DE was defined as combined expression of MYC and BCL2.

\section{Fluorescence in situ hybridization}

Fluorescence in situ hybridization (FISH) was performed with Vysis Dual Color Break Apart Rearrangement Probes from Abbott using the Dako Histology FISH Accessory Kit, according to 
standard procedures. All cases were manually scored by A.M.R.S and J.K.K. and considered rearranged with a split of the signals in $\geq 10 \%$ of the tumor cells. In case of a $M Y C$ rearrangement, additional FISH for BCL2 and BCL6 was performed with Vysis Dual Color Break Apart Rearrangement Probes from Abbott and the Dako Histology FISH Accessory Kit, according to the same procedures. In the PCFCL group, FISH for BCL2 was also performed on cases with BCL2 expression.

\section{Statistical analysis}

Statistical analysis was performed using IBM SPSS Statistics 23. Survival was defined as the date of diagnosis until the date of death by any cause (OS) or the date of death from lymphoma (DSS). Disease-free survival (DFS) was calculated from the date of diagnosis until the time of relapse or progression of disease or death from lymphoma. Patients without an event at the last date of follow-up were censored. For the DSS and DFS, patients who died from an unrelated cause were also censored. Comparison between the subgroups based on MYC rearrangements and DE occurred with the Mann-Whitney $U$ test for continuous data and the $\chi^{2}$ for categorical data. Survival curves were plotted using the Kaplan-Meier method and compared with the Log-rank test. Corresponding hazard ratios $(\mathrm{HR})$ and their $95 \%$ confidence intervals $(95 \% \mathrm{Cl})$ were calculated in a Cox proportionalhazards model. A p-value of $<0.05$ was considered statistically significant.

\section{RESULTS}

In total, 44 patients with PCDLBCL-LT were included: 25 (57\%) females and 19 (43\%) males. The patient characteristics and an overview of the results are presented in Table 1 and Figure 1. The median age at diagnosis was 78 (range, 49 to 92) years. At presentation, disease was located on the legs in $35(80 \%)$ patients and in sites other than the legs in $9(20 \%)$ patients. Extent of disease was solitary in 11 (25\%) patients, localized (multiple lesions in one body region) in 28 (64\%) patients, and generalized (multiple lesions in more than one body region) in 5 (11\%) patients. Histologically, the skin lesions showed a diffuse infiltrate of centroblasts and immunoblasts throughout the entire dermis, in some cases extending into the subcutaneous tissue (Figure 2). These B-cells showed uniform and strong expression of BCL2 in 42 (95\%) cases, MUM1 in 36 (84\%) cases and IgM in 42 (95\%) cases, while expression of CD10 was seen in 7 (16\%) patients, with a very weak expression in 3 of them. In addition, BCL6 was positive in $27(61 \%)$ patients.

The PCFCL group consisted of 17 patients, including 5 (29\%) females and 12 (71\%) males. Patients were diagnosed at a median age of 58 (range, 46 to 69 ) years. In all patients, lesions were located on the head or trunk, and in one patient also one leg was involved. Histologically, the growth pattern was follicular in $2(12 \%)$ cases, follicular/diffuse in 4 (24\%) cases, and diffuse in 11 (65\%) 
cases. The tumor cells were positive for BCL6 in all cases and for CD10 in $14(82 \%)$ cases, while none of the cases expressed MUM1. BCL2 was expressed in 2 (12\%) cases, of which one harbored a BCL2 rearrangement. Two other cases (12\%) had membranous staining of IgM.

\section{Follow-up and survival}

The PCDLBCL-LT patients were initially treated with immunochemotherapy (CHOP with rituximab) in 16 (36\%) cases, chemotherapy (CHOP) in 6 (14\%) cases, local radiotherapy in 20 (45\%) cases, and surgery alone in $1(2 \%)$ case. In one other patient $(2 \%)$, no treatment was given due to spontaneous remission of a solitary lesion. After initial therapy, 41 (93\%) patients reached complete remission. Twenty-three (52\%) patients developed cutaneous relapses during follow-up and 15 patients (34\%) had relapses at extracutaneous sites. The median disease-free period was 12 (range, 0 to 105 ) months. After a median duration of follow-up of 41 (range, 4 to 125) months, 15 (34\%) patients were still alive with or without ongoing disease, 20 (45\%) patients died from lymphoma and 9 (20\%) patients died from an unrelated cause. In our cohort of PCDLBCL-LT patients, OS was $46 \%$, DSS was $52 \%$, and DFS was $39 \%$ at 5 years.

In the PCFCL group, all cases reached complete remission after initial treatment. The median duration of follow-up was 63 (range, 4 to 224) months during which skin relapses occurred in 11 (65\%) patients, and 2 (12\%) patients had extracutaneous dissemination (in both cases to lymph nodes). After follow-up, all patients were still alive with or without ongoing disease, resulting in a 5year OS and DSS of $100 \%$.

\section{MYC rearrangements and DE}

In total, 14 (32\%) PCDLBCL-LT cases showed a rearrangement of the MYC gene, with a double hit of BCL6 in 2 of them. No double hits with BCL2 were present. Interestingly, CD10 expression was only observed in patients with wild type MYC. DE was seen in 28 of 43 (65\%) patients, including 12 of the 14 (86\%) cases with a MYC rearrangement and one of the 2 cases with a double hit (Figure 2). The other double hit case was negative for MYC with expression in $~ 30 \%$ of the tumor cells. As $95 \%$ of the patients with PCDLBCL-LT expressed BCL2, the frequency of DE (65\%) was similar to expression of MYC alone (29/43; 67\%).

All 17 cases of PCFCL were MYC-wild type and none of the cases expressed MYC. In 15 (88\%) cases, MYC was only expressed by $<10 \%$ of the tumor cells, and the remaining 2 cases expressed MYC in $\sim 20 \%$ of the tumor cells. For comparison, in the PCDLBCL-LT group, only 4 of 43 (9\%) cases expressed MYC in $<10 \%$ of the tumor cells. As MYC was always negative, none of the PCFCL cases were double expressors. 
Prognostic factors

In PCDLBCL-LT patients, the presence of a MYC rearrangement was associated with a statistically significantly reduced 5-year DSS (Log-rank, $p=0.036 ; \mathrm{HR}, 2.67 ; 95 \% \mathrm{Cl}, 1.03-6.96$; Figure $3 \mathrm{~A}$ ) and DFS (Log-rank, $\mathrm{p}=0.028 ; \mathrm{HR}, 2.47 ; 95 \% \mathrm{Cl}, 1.05-5.78$; Figure $3 \mathrm{~B}$ ), but not with a reduced OS (Log-rank, $\mathrm{p}=0.157 ; \mathrm{HR}, 1.87 ; 95 \% \mathrm{Cl}, 0.77-4.53$; Figure 3C). Expression of MYC alone or in combination with BCL2 (DE) had no adverse effect on survival (data not shown).

The two PCDLBCL-LT patients with a double hit had a favorable disease course. Notably, in both patients disease was located on the abdomen and not on the legs (Figure 2). Both patients were initially treated with radiotherapy with complete regression of the lesions. One patient remained disease-free and died after 86 months from an unrelated cause, while the other double hit patient developed positive inguinal lymph nodes after 17 months of follow-up, but reached complete remission after R-CHOP treatment (8x) with a total follow-up duration of 40 months.

\section{DISCUSSION}

In the present study, we investigated the frequency and prognostic significance of MYC rearrangements with or without a double hit in BCL2 and/or BCL6 and of DE in 44 patients with PCDLBCL-LT and 17 patients with PCFCL.

A subset of $32 \%$ of the PCDLBCL-LT patients had a rearrangement of the MYC gene, with a double hit in BCL6 in 2 of these patients, while all PCFCL cases were MYC-wild type. The percentage of MYC rearrangements in PCDLBCL-LT falls within the wide range of the previously reported studies with small patient numbers ( $0 \%$ to $43 \%) .(22,24-26)$ Our frequency, however, is higher than reported in nodal DLBCL (9 to $14 \%)(5-8)$ and other extranodal DLBCL, such as DLBCL of the central nervous system (CNS-DLBCL) (up to 9\%) (28-30). Similar to nodal DLBCL in which MYC rearrangements are associated with a poor outcome, PCDLBCL-LT patients with a MYC rearrangement had a statistically significant inferior 5-year DSS and DFS compared with PCDLBCL-LT patients without a MYC rearrangement (Figure 3).

To the best of our knowledge, this is the first study that reports the presence of double hits in PCDLBCL-LT patients. In our cohort, 2 of the MYC-rearranged patients had a double hit in BCL6. A double hit with $B C L 6$ instead of $B C L 2$ is in line with expectations, as in nodal DLBCL with an $A B C$ phenotype, double hits with $B C L 2$ do not occur.(17) Similarly, in CNS-DLBCL, that also has an $A B C$ phenotype, a case report describes a patient with a double hit involving BCL6 and not BCL2.(29) Notably, the disease course of the PCDLBCL-LT patients with a double hit seemed favorable compared with the patients with a single or no MYC rearrangement, but the number is too small to 
draw any conclusions. This finding, however, is in line with the presence of a double hit in BCL6 instead of $B C L 2$, as in nodal DLBCL, the association with poor outcome especially accounts for cases with a double hit in $B C L 2$ or triple hits, and less for patients with a double hit in $B C L 6 .(6,7,31)$ Despite the GCB-phenotype of PCFCL, no MYC hits, nor double hits, were present in our group of PCFCL patients. This is in line with previous studies $(24,32)$, except for one study that reported DE in 6/21 (29\%) cases of PCFCL including one case with a double hit in MYC and BCL6.(26)

In contrast to reported studies in nodal DLBCL $(14,15)$ and CNS-DLBCL $(33-35)$, DE was not associated with an inferior survival in our cohort of patients with PCDLBCL-LT. Few studies with a limited number of patients evaluated the prognostic significance of $D E$ in $C B C L$, showing an inferior survival for the group as a whole -as can be expected by the differences in immune profile and prognosis of PCDLBCL-LT and PCFCL patients-, but with contradicting results for only the PCDLBCL-LT patients. $(26,32)$ As almost all cases of PCDLBCL-LT expressed BCL2, which is a known characteristic of this disease $(19,20)$, the percentage of DE (65\%) was similar to MYC expression alone (67\%). The percentage of DE in our cohort of PCDLBCL-LT patients corresponds with previously reported percentages of 55 to $83 \%$. $(22,26,32)$ In addition, MYC protein expression was not suitable for the prediction of a MYC rearrangement with especially a low positive predictive value of $41 \%$. Some studies suggest that a cutoff value of $70 \%$ for MYC has the highest predictive value(36), however, this was not confirmed in our study with only a slight improvement of the positive predictive value to $56 \%$.

On the basis of our results with high frequency and prognostic significance of MYC rearrangements in PCDLBCL-LT but not PCFCL, we suggest that it may be useful to perform MYC-FISH in all newly diagnosed PCDLBCL-LT patients, as is currently also standard practice in newly diagnosed nodal DLBCL patients.(27) Because of the rarity of double hits in our cohort, the absence in previous studies $(22,24)$, and the combination of a double hit with $B C L 6$ instead of $B C L 2$, additional FISH for $B C L 2$ and BCL6 in case of a MYC rearrangement seems to have no clinical relevance in patients with PCDLBCL-LT. Immunostaining for MYC protein may be used as an adjunctive marker to differentiate between PCDLBCL-LT and PCFCL with a diffuse large cell morphology in equivocal cases, but is not useful as a prognostic marker, nor as a predictive marker for a $M Y C$ rearrangement.

This study demonstrates that MYC-rearranged PCDLBCL-LT patients may need more intensive disease monitoring during follow-up due to the higher risk for disease-progression and death from lymphoma. Also, the presence of a MYC rearrangement in PCDLBCL-LT patients may be interesting with regard to therapeutic strategies, such as intensifying chemotherapeutic regimens using dose-adjusted EPOCH-R instead of R-CHOP, which is also well tolerated in patients older than 
60 years.(37) Moreover, in the future possible new therapies may be developed targeting the MYC pathway with restoration of the immune response.(38)

In conclusion, this study identifies a high incidence of MYC rearrangements in PCDLBCL-LT but not PCFCL and suggests that PCDLBCL-LT patients with a MYC rearrangement have a higher risk for disease-progression and death from lymphoma. Therefore, it may be useful to perform MYC-FISH in all newly diagnosed PCDLBCL-LT patients.

\section{REFERENCES}

1. Willemze R, Jaffe ES, Burg G, et al. WHO-EORTC classification for cutaneous lymphomas. Blood. 2005;105(10):3768-85.

2. Senff NJ, Zoutman $\mathbf{W H}$, Vermeer $\mathbf{M H}$, et al. Fine-mapping chromosomal loss at 9p21: correlation with prognosis in primary cutaneous diffuse large B-cell lymphoma, leg type. J Invest Dermatol. 2009;129(5):1149-55.

3. Pham-Ledard A, Beylot-Barry M, Barbe $C$, et al. High frequency and clinical prognostic value of MYD88 L265P mutation in primary cutaneous diffuse large B-cell lymphoma, leg-type. JAMA Dermatol. 2014;150(11):1173-9.

4. Grange F, Bekkenk MW, Wechsler J, et al. Prognostic factors in primary cutaneous large Bcell lymphomas: a European multicenter study. J Clin Oncol. 2001;19(16):3602-10.

5. Barrans S, Crouch S, Smith A, et al. Rearrangement of MYC is associated with poor prognosis in patients with diffuse large B-cell lymphoma treated in the era of rituximab. J Clin Oncol. 2010;28(20):3360-5.

6. Copie-Bergman C, Cuilliere-Dartigues $P$, Baia M, et al. MYC-IG rearrangements are negative predictors of survival in DLBCL patients treated with immunochemotherapy: a GELA/LYSA study. Blood. 2015;126(22):2466-74.

7. Tzankov A, Xu-Monette ZY, Gerhard M, et al. Rearrangements of MYC gene facilitate risk stratification in diffuse large B-cell lymphoma patients treated with rituximab-CHOP. Mod Pathol. 2014;27(7):958-71.

8. Savage KJ, Johnson NA, Ben-Neriah S, et al. MYC gene rearrangements are associated with a poor prognosis in diffuse large B-cell lymphoma patients treated with R-CHOP chemotherapy. Blood. 2009;114(17):3533-7.

9. Aukema SM, Siebert R, Schuuring E, et al. Double-hit B-cell lymphomas. Blood. 2011;117(8):2319-31. 
10. Swerdlow SH. Diagnosis of 'double hit' diffuse large B-cell lymphoma and B-cell lymphoma, unclassifiable, with features intermediate between DLBCL and Burkitt lymphoma: when and how, FISH versus IHC. Hematology Am Soc Hematol Educ Program. 2014;2014(1):90-9.

11. Clipson A, Barrans S, Zeng N, et al. The prognosis of MYC translocation positive diffuse large B-cell lymphoma depends on the second hit. J Pathol Clin Res. 2015;1(3):125-33.

12. Johnson NA, Savage KJ, Ludkovski O, et al. Lymphomas with concurrent BCL2 and MYC translocations: the critical factors associated with survival. Blood. 2009;114(11):2273-9.

13. Swerdlow SH, editor. WHO Classification of Tumours of Haematopoietic and Lymphoid Tissues. Revised 4th ed. Lyon: IARC; 2017.

14. Hu S, Xu-Monette ZY, Tzankov A, et al. MYC/BCL2 protein coexpression contributes to the inferior survival of activated B-cell subtype of diffuse large B-cell lymphoma and demonstrates highrisk gene expression signatures: a report from The International DLBCL Rituximab-CHOP Consortium Program. Blood. 2013;121(20):4021-31; quiz 250.

15. Green TM, Young $\mathrm{KH}$, Visco $\mathrm{C}$, et al. Immunohistochemical double-hit score is a strong predictor of outcome in patients with diffuse large B-cell lymphoma treated with rituximab plus cyclophosphamide, doxorubicin, vincristine, and prednisone. J Clin Oncol. 2012;30(28):3460-7.

16. Rosenthal A, Younes A. High grade B-cell lymphoma with rearrangements of MYC and BCL2 and/or BCL6: Double hit and triple hit lymphomas and double expressing lymphoma. Blood Rev. 2017;31(2):37-42.

17. Scott DW, King RL, Staiger AM, et al. High grade B-cell lymphoma with MYC and BCL2 and/or BCL6 rearrangements with diffuse large B-cell lymphoma morphology. Blood. 2018.

18. Hoefnagel JJ, Dijkman R, Basso K, et al. Distinct types of primary cutaneous large B-cell lymphoma identified by gene expression profiling. Blood. 2005;105(9):3671-8.

19. Senff NJ, Hoefnagel JJ, Jansen PM, et al. Reclassification of 300 primary cutaneous B-Cell lymphomas according to the new WHO-EORTC classification for cutaneous lymphomas: comparison with previous classifications and identification of prognostic markers. J Clin Oncol. 2007;25(12):15817.

20. Kodama K, Massone C, Chott A, et al. Primary cutaneous large B-cell lymphomas: clinicopathologic features, classification, and prognostic factors in a large series of patients. Blood. 2005;106(7):2491-7.

21. Koens L, Zoutman WH, Ngarmlertsirichai P, et al. Nuclear factor-kappaB pathway-activating gene aberrancies in primary cutaneous large B-cell lymphoma, leg type. J Invest Dermatol. 2014;134(1):290-2. 
22. Pham-Ledard A, Prochazkova-Carlotti M, Andrique L, et al. Multiple genetic alterations in primary cutaneous large B-cell lymphoma, leg type support a common lymphomagenesis with activated B-cell-like diffuse large B-cell lymphoma. Mod Pathol. 2014;27(3):402-11.

23. Mareschal S, Pham-Ledard A, Viailly PJ, et al. Identification of somatic mutations in primary cutaneous diffuse large B-cell lymphoma, leg-type by massive parallel sequencing. J Invest Dermatol. 2017.

24. Hallermann C, Kaune KM, Gesk S, et al. Molecular cytogenetic analysis of chromosomal breakpoints in the IGH, MYC, BCL6, and MALT1 gene loci in primary cutaneous B-cell lymphomas. J Invest Dermatol. 2004;123(1):213-9.

25. Wiesner T, Streubel B, Huber D, et al. Genetic aberrations in primary cutaneous large B-cell lymphoma: a fluorescence in situ hybridization study of 25 cases. Am J Surg Pathol. 2005;29(5):66673.

26. Menguy S, Frison E, Prochazkova-Carlotti M, et al. Double-hit or dual expression of MYC and BCL2 in primary cutaneous large B-cell lymphomas. Mod Pathol. 2018.

27. Swerdlow SH, Campo E, Pileri SA, et al. The 2016 revision of the World Health Organization classification of lymphoid neoplasms. Blood. 2016;127(20):2375-90.

28. Gill KZ, Iwamoto F, Allen A, et al. MYC Protein Expression in Primary Diffuse Large B-Cell Lymphoma of the Central Nervous System. Plos One. 2014;9(12).

29. Brunn A, Nagel I, Montesinos-Rongen $M$, et al. Frequent triple-hit expression of MYC, BCL2, and BCL6 in primary lymphoma of the central nervous system and absence of a favorable MYC(low)BCL2(low) subgroup may underlie the inferior prognosis as compared to systemic diffuse large B cell lymphomas. Acta Neuropathol. 2013;126(4):603-5.

30. Cady FM, O'Neill BP, Law ME, et al. Del(6)(q22) and BCL6 Rearrangements in primary CNS lymphoma are indicators of an aggressive clinical course. Journal of Clinical Oncology. 2008;26(29):4814-9.

31. Ye $Q$, Xu-Monette $Z Y$, Tzankov A, et al. Prognostic impact of concurrent MYC and BCL6 rearrangements and expression in de novo diffuse large B-cell lymphoma. Oncotarget. 2016;7(3):2401-16.

32. Lucioni M, Berti E, Arcaini L, et al. Primary cutaneous B-cell lymphoma other than marginal zone: clinicopathologic analysis of 161 cases: Comparison with current classification and definition of prognostic markers. Cancer Med. 2016;5(10):2740-55.

33. Tapia G, Baptista MJ, Munoz-Marmol AM, et al. MYC protein expression is associated with poor prognosis in primary diffuse large B-cell lymphoma of the central nervous system. Apmis. 2015;123(7):596-603. 
34. Kim S, Nam SJ, Kwon D, et al. MYC and BCL2 overexpression is associated with a higher class of Memorial Sloan-Kettering Cancer Center prognostic model and poor clinical outcome in primary diffuse large B-cell lymphoma of the central nervous system. Bmc Cancer. 2016;16.

35. Shi QY, Feng $X, B a o W$, et al. MYC/BCL2 Co-Expression Is a Stronger Prognostic Factor Compared With the Cell-of-Origin Classification in Primary CNS DLBCL. J Neuropath Exp Neur. 2017;76(11):942-8.

36. Green TM, Nielsen $\mathrm{O}$, de Stricker $\mathrm{K}$, et al. High levels of nuclear MYC protein predict the presence of MYC rearrangement in diffuse large B-cell lymphoma. Am J Surg Pathol. 2012;36(4):6129.

37. Dunleavy K. Aggressive B cell Lymphoma: Optimal Therapy for MYC-positive, Double-Hit, and Triple-Hit DLBCL. Curr Treat Options Oncol. 2015;16(12):58.

38. Casey SC, Baylot V, Felsher DW. The MYC Oncogene is a Global Regulator of the Immune Response. Blood. 2018. 


\section{FIGURE LEGENDS}

FIGURE 1. Overview of results of FISH for MYC, BCL2, and BCL6 and immunohistochemistry for MYC and BCL2 in 44 patients with PCDLBCL-LT. OncoPrinter plot showing a MYC rearrangement in $32 \%$ of the patients with a double hit in BCL6 in 4\%, and no double hits in BCL2. Protein expression of MYC was present in $67 \%$ and BCL2 in $95 \%$ with double expression of MYC and BCL2 in $65 \%$ of the patients.

FIGURE 2. Clinical presentation, histology, and FISH of a patient with PCDLBCL-LT with a double hit in MYC and BCL6. The skin of the lower abdomen shows brown to reddish, infiltrated tumors (A). The skin biopsy (HE 1 [B], HE 2 [C]) contains diffuse dermal sheets of large, blastic cells with prominent nucleoli, and mitotic figures with infiltration of the subcutaneous tissue and sparing of the epidermis. The tumor cells are positive for CD20 (D), MUM1 (F), IgM (G), BCL2 (I), and MYC (H), but negative for CD10 (E) and BCL6 (J). Stainings: HE 1, HE 2, and immunohistochemical. FISH shows rearrangements of $M Y C(K)$ and $B C L 6(M)$, and no rearrangement of $B C L 2(L)$.

FIGURE 3. Survival analysis for MYC status in $\mathbf{4 4}$ patients with PCDLBCL-LT. Kaplan-Meier survival curves show a statistically significant adverse effect on (A) DSS (Log-rank, $p=0.036 ; \mathrm{HR}, 2.67 ; 95 \% \mathrm{Cl}$, 1.03-6.96), and (B) DFS (Log-rank, p=0.028; HR, 2.47; 95\% Cl, 1.05-5.78), but not on (C) OS of the patients (Log-rank, $\mathrm{p}=0.157 ; \mathrm{HR}, 1.87 ; 95 \% \mathrm{Cl}, 0.77-4.53$ ) at 5 years. Survival was defined as the date of diagnosis until the date of death by any cause (OS) or the date of death from lymphoma (DSS). DFS was calculated from the date of diagnosis until the time of progression or relapse of disease or death from lymphoma. Patients without an event at the last date of follow-up were censored. 
Table 1. Patient characteristics and overview of results of 44 patients with primary cutaneous diffuse large B-cell lymphoma, leg type

\begin{tabular}{|c|c|c|c|c|c|c|c|}
\hline \multirow[t]{2}{*}{ Characteristic } & \multirow{2}{*}{$\begin{array}{c}\text { Total } \\
(n=44)\end{array}$} & \multicolumn{2}{|c|}{ MYC status } & \multirow[b]{2}{*}{$p$-value* } & \multicolumn{2}{|c|}{ Double expression $^{\mathrm{a}}$} & \multirow[b]{2}{*}{$\mathrm{p}$-value** } \\
\hline & & $\begin{array}{c}\text { rearranged } \\
(n=14)\end{array}$ & $\begin{array}{c}\text { wild type } \\
(n=30)\end{array}$ & & $\begin{array}{c}\text { present } \\
(n=28)\end{array}$ & $\begin{array}{l}\text { absent } \\
(n=15)\end{array}$ & \\
\hline Gender, n (\%) & & & & .976 & & & .811 \\
\hline - female & $25(57)$ & $8(57)$ & $17(57)$ & & $16(57)$ & $8(53)$ & \\
\hline male & $19(43)$ & $6(43)$ & $13(43)$ & & $12(43)$ & $7(47)$ & \\
\hline Age at diagnosis in years, median (range) & $78(49-92)$ & $78.5(49-86)$ & $78(53-92)$ & .622 & $78.5(49-90)$ & $78(53-92)$ & .540 \\
\hline Disease localisation, $\mathrm{n}(\%)$ & & & & .362 & & & .499 \\
\hline - legs & $35(80)$ & $10(71)$ & $25(83)$ & & $23(82)$ & $11(73)$ & \\
\hline - $\quad$ other sites & $9(20)$ & $4(29)$ & $5(17)$ & & $5(18)$ & $4(27)$ & \\
\hline Extent of disease, $\mathrm{n}(\%)$ & & & & .250 & & & .220 \\
\hline - $\quad$ solitary & $11(25)$ & $2(14)$ & $9(30)$ & & $6(21)$ & $4(27)$ & \\
\hline - $\quad$ localized & $28(64)$ & $9(64)$ & $19(63)$ & & $17(61)$ & $11(73)$ & \\
\hline - $\quad$ generalized & $5(11)$ & $3(21)$ & $2(7)$ & & $5(18)$ & - & \\
\hline Initial therapy, n (\%) & & & & .035 & & & .128 \\
\hline - local therapy ${ }^{b}$ & $21(48)$ & $3(21)$ & $18(60)$ & & $11(39)$ & $9(60)$ & \\
\hline - $\quad$ immunochemotherapy $(\mathrm{R}-\mathrm{CHOP})^{\mathrm{c}}$ & $16(36)$ & $6(43)$ & $10(33)$ & & $10(36)$ & $6(40)$ & \\
\hline - $\quad$ chemotherapy $(\mathrm{CHOP})^{\mathrm{c}}$ & $6(14)$ & $4(29)$ & $2(7)$ & & $6(21)$ & - & \\
\hline - $\quad$ no treatment ${ }^{\mathrm{d}}$ & $1(2)$ & $1(7)$ & - & & $1(4)$ & - & \\
\hline Status at last follow-up, n (\%) & & & & .157 & & & .283 \\
\hline - $\quad$ alive $\mathrm{w} / \mathrm{o}$ disease & $11(25)$ & $1(7)$ & $10(33)$ & & $5(18)$ & $6(40)$ & \\
\hline - $\quad$ alive $\mathrm{w} /$ disease & $4(9)$ & $2(14)$ & $2(7)$ & & $3(11)$ & $1(7)$ & \\
\hline - $\quad$ died of lymphoma & $20(45)$ & $9(64)$ & $11(37)$ & & $13(46)$ & $7(47)$ & \\
\hline - $\quad$ died unrelated & $9(20)$ & $2(14)$ & $7(23)$ & & $7(25)$ & $1(7)$ & \\
\hline 5-year overall survival, \% & 46 & 30 & 52 & .157 & 44 & 53 & .718 \\
\hline 5-year disease-specific survival, \% & 52 & 30 & 62 & .036 & 51 & 53 & .898 \\
\hline 5-year disease-free survival, $\%$ & 44 & 25 & 53 & .028 & 41 & 49 & .815 \\
\hline Immunophenotype, n (\%) & & & & & & & \\
\hline - $\quad M Y C^{a}$ & $29(67)$ & $12(86)$ & $17(59)$ & .086 & $28(100)$ & $1(7)$ & NA \\
\hline$-\quad \mathrm{CD} 10$ & $7(16)$ & $0(0)$ & $7(23)$ & .049 & $6(21)$ & $1(7)$ & .211 \\
\hline - $\quad$ BCL6 & $27(61)$ & $6(43)$ & $21(70)$ & .085 & $18(64)$ & $8(53)$ & .484 \\
\hline - $\quad M U M 1^{a}$ & $36(84)$ & $10(71)$ & $26(90)$ & .129 & $23(82)$ & $13(87)$ & .702 \\
\hline $\mathrm{BCL} 2$ & $42(95)$ & $14(100)$ & $28(93)$ & .323 & $28(100)$ & $13(87)$ & NA \\
\hline $\lg M$ & $42(95)$ & $13(93)$ & $29(97)$ & .572 & $27(96)$ & $14(93)$ & .646 \\
\hline MYC status, $\mathrm{n}(\%)$ & & & & NA & & & .049 \\
\hline - rearrangement & $14(32)$ & NA & NA & & $12(43)$ & $2(13)$ & \\
\hline - $\quad$ wild type & $30(68)$ & & & & $16(57)$ & $13(87)$ & \\
\hline Double hit ${ }^{\mathrm{e}}$ & $2(4)$ & $2(14)$ & NA & NA & $1(4)$ & $1(7)$ & .646 \\
\hline
\end{tabular}

Abbreviations: $\mathrm{R}-\mathrm{CHOP}$, rituximab with cyclophosphamide, doxorubicin, vincristine, and prednisone; $\mathrm{CHOP}$,

cyclophosphamide, doxorubicin, vincristine, and prednisone; NA, not applicable.

aData is missing in one case.

bLocal therapy consisted of radiotherapy alone in 19 patients, radiotherapy with surgical excision in one patient, and surgical excision alone in one patient.

c(Immuno)chemotherapy was combined with radiotherapy in nine patients.

dNo treatment was given due to spontaneous remission of the solitary lesion.

eDouble hits occurred only in combination with $B C L 6$, not with BCL2.

*Comparison between MYC-rearranged and MYC-wild type patients.

**Comparison between patients with and without double expression of MYC and BCL2. 


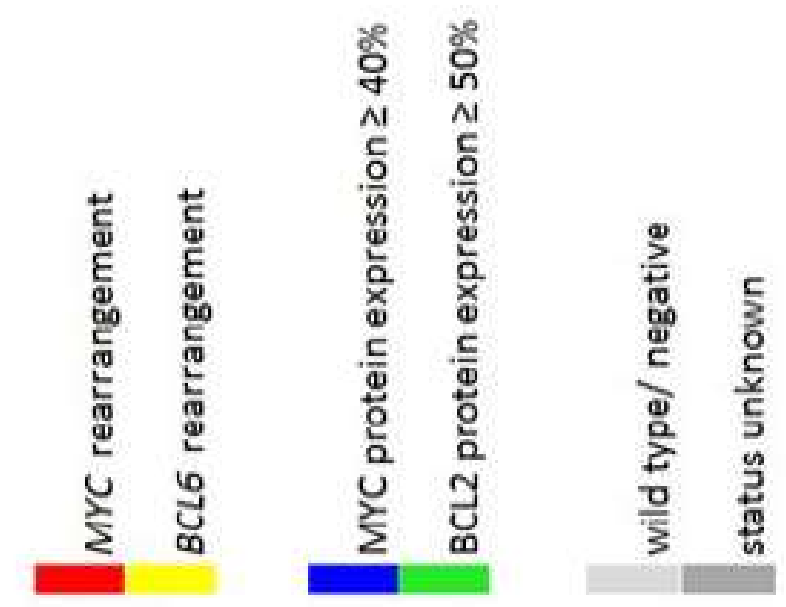

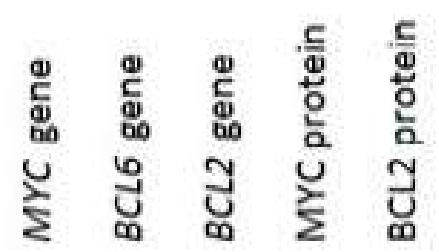

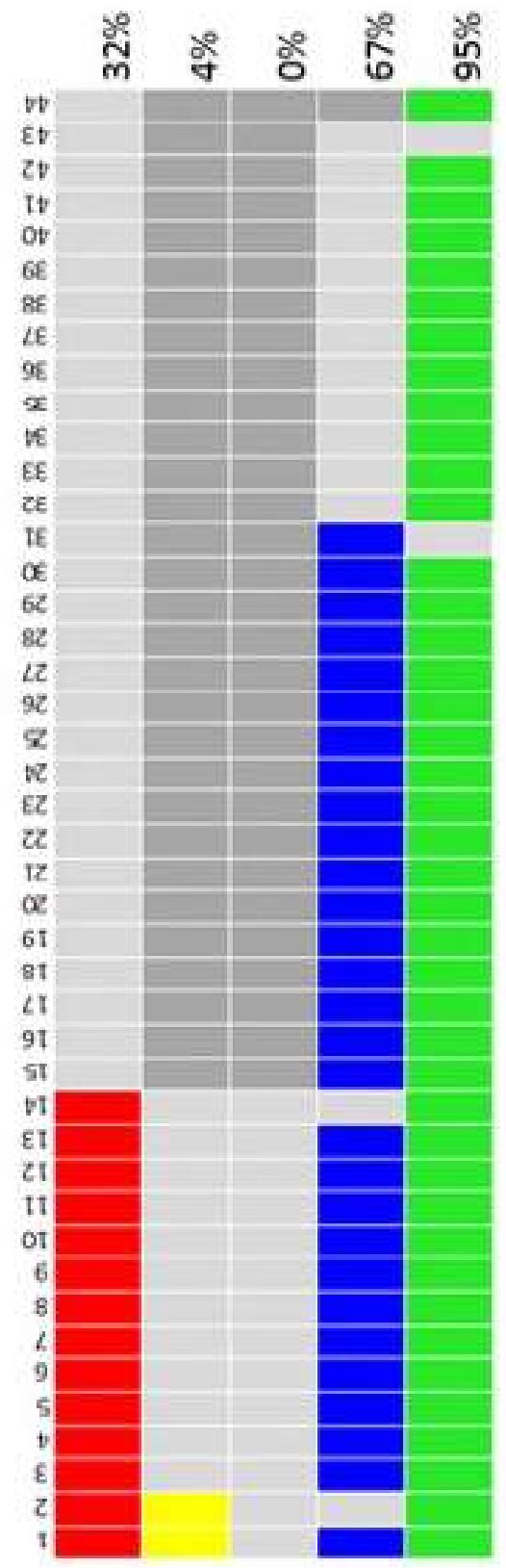




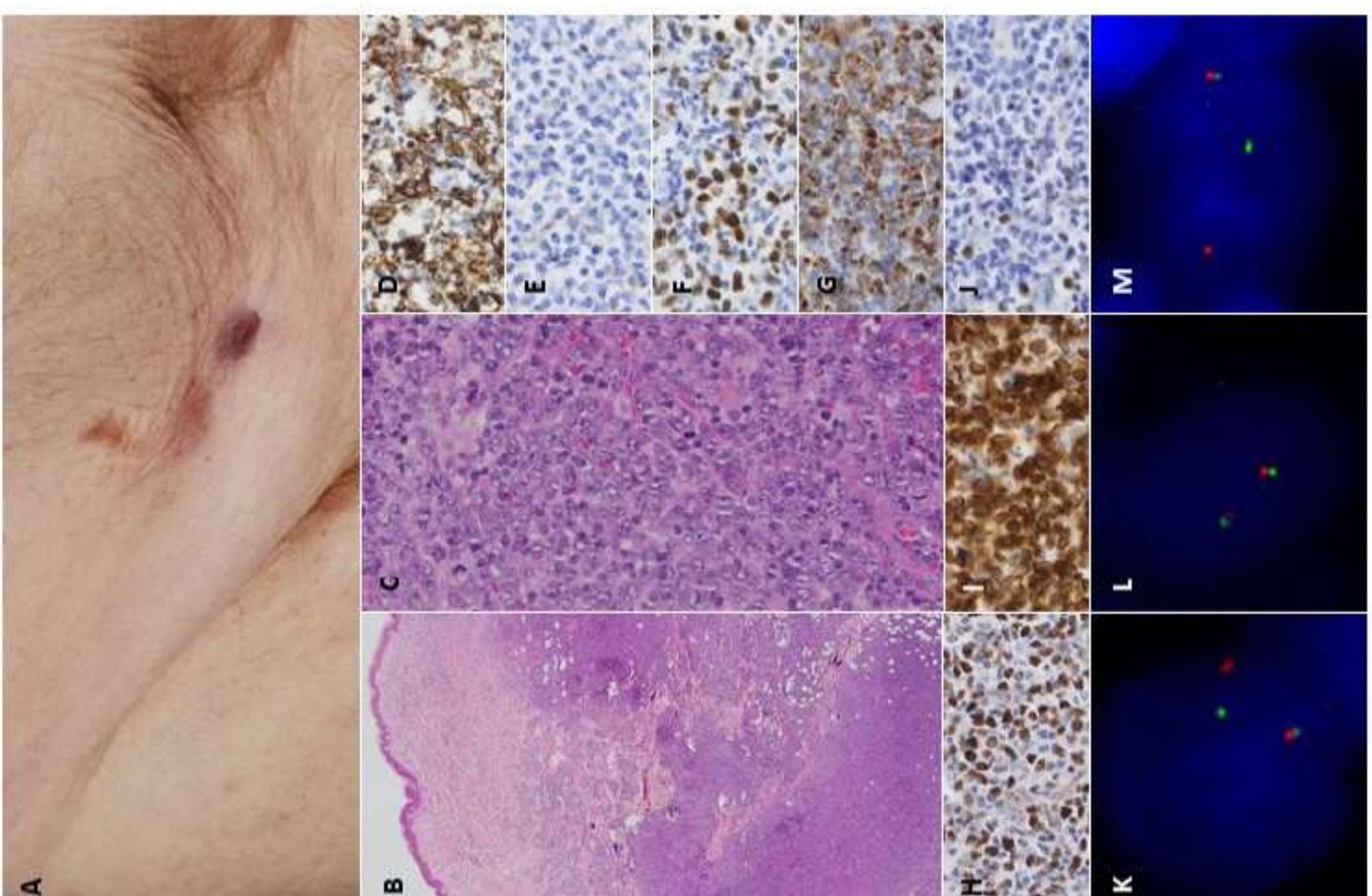


(syzuou) จயщц

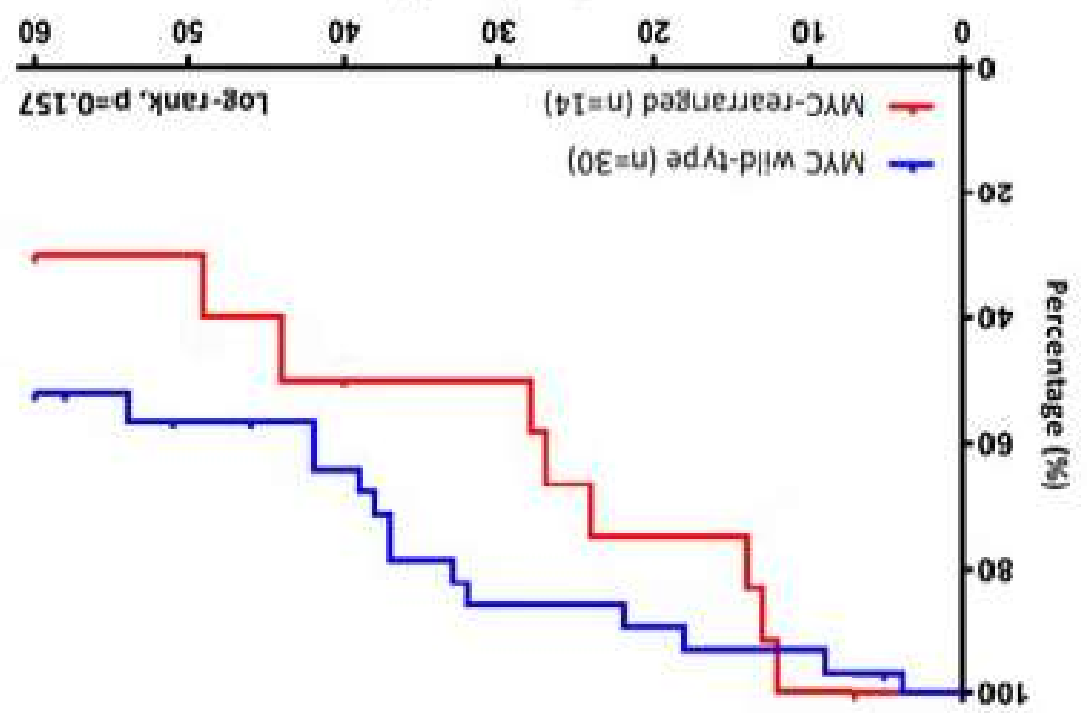

ว

ןen!̣uns ||едало

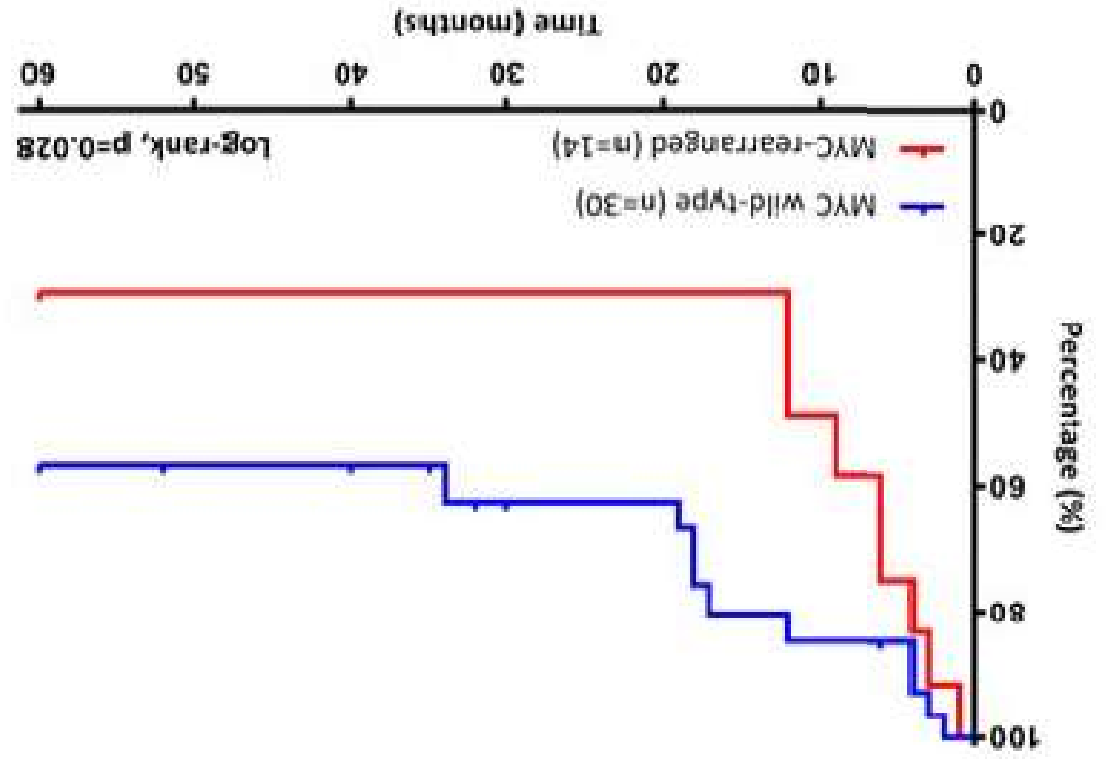

g

[en!̣uns aas\}-aseas!̣

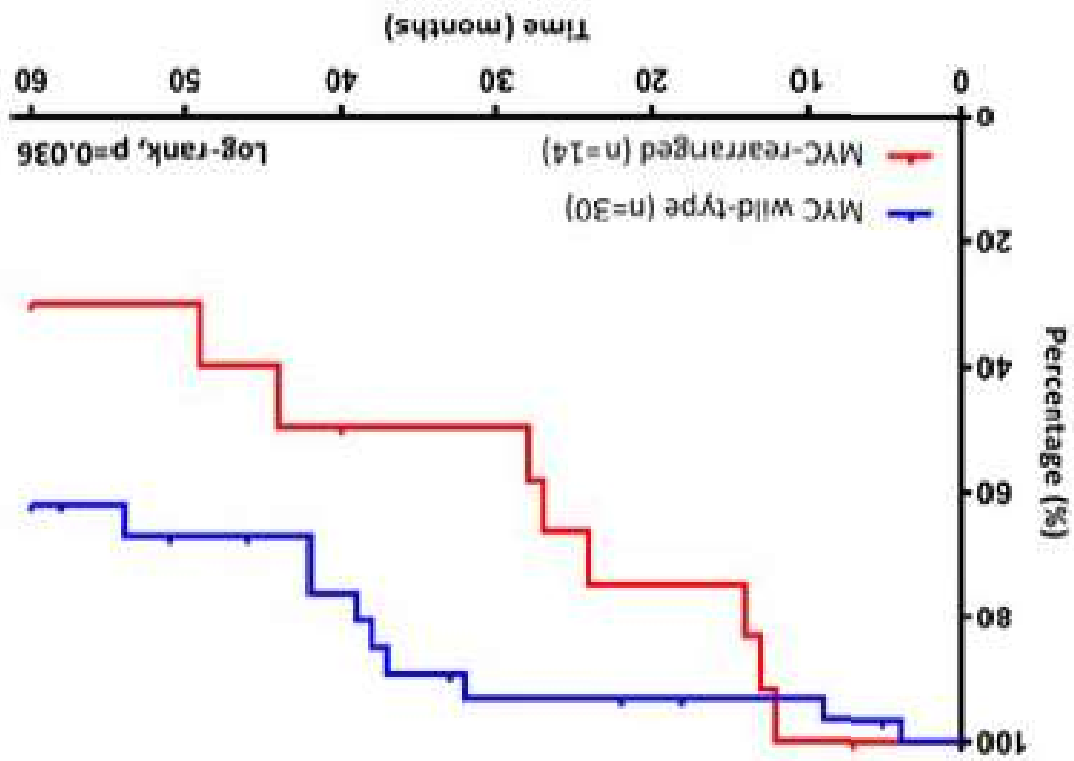

